\title{
Internet and electronic information management
}

\author{
Yaşar Tonta \\ Hacettepe University, Department of Information Management, 06532 Beytepe, Ankara, Turkey \\ E-mail: tonta@hacettepe.edu.tr
}

\begin{abstract}
The number and types of information sources accessible through the Internet are ever increasing. Billions of documents including text, pictures, sound, and video are readily available for both scholarly and every-day uses. Even libraries and information centers with sizable budgets are having difficulties in coping with this increase. More developed tools and methods are needed to find, filter, organize and summarize electronic information sources. This paper is an overview of a wide variety of electronic information management issues ranging from infrastructure to the integration of information technology and content, from personalization of information services to "disintermediation". It discusses the issues of description, organization, collection management, preservation and archiving of electronic information.
\end{abstract}

\section{Introduction}

Lyman and Varian [17] estimate the amount of new information produced in the world in 2002 to be around five exabytes (one exabyte $=$ one billion gigabytes, or $10^{18}$ bytes). "Five exabytes of information is equivalent in size to the information contained in 37,000 new libraries the size of the Library of Congress book collections" and "the amount of new information stored on paper, film, magnetic, and optical media has about doubled in the last three years" [17]. Printed documents of all kinds constitute only $0.01 \%$ of the total whereas information recorded on magnetic media such as personal computers' hard disks constitutes an overwhelming majority (92\%) of the overall information production. Lyman and Varian [17] point out that "almost $800 \mathrm{MB}$ of recorded information is produced per person each year" and they "estimate that new stored information grew about 30\% a year between 1999 and 2002".

We are faced with an enormous rate of increase of electronic information. The annual growth rate for information available through the Internet was about $300 \%$ during the early years, although there are some signs that the growth rate of the public web is leveling off in the last couple of years [18]. The Library of Congress, one of the largest libraries in the world, has accumulated some 170 million items over decades. Yet the number of documents on the "surface Web" accessible through regular search engines such as Google is estimated to be around 15 billion; it was about just 2.3 billion in 2000 [1]. If dynamically created web pages, documents and databases available through the enterprise intranets, are included, the number of documents went up to 550 billion! Such resources are usually behind the firewalls and therefore not directly accessible through search engines (hence called the "deep Web") [1]. As of Summer 2003, the volume of information on the surface web and the deep web was measured as about 167 terabytes and 91,850 terabytes (upper estimate), respectively [17].

As more information sources are born digital (or later become digital) and publicly accessible through the Internet, the relative importance of the management of information in personal, organizational and 
societal levels also increases tremendously. This makes the management and retrieval of information from large quantities of electronic sources all the more important. We are expected to know how to discover, find, filter, gather, organize, store, and get access to recorded information. We need to be avid "consumers" of information to manage our professional and personal lives successfully. We should have "information literacy" skills to handle computer hardware, software and networks to find information. As Toffler [28] warns us, the ignorants of the future are going to be those who do not know how to find and get access to relevant information (so-called "information illiterates").

Several philosophers have given considerable thought to knowledge, classification, and problems related with the recording, storage and retrieval of information. Plato, for instance, raises what is called "Meno's Paradox" and draws attention to the difficulties of searching for knowledge. The following dialogue between Meno and Socrates reflects this:

"Meno. But how will you look for something when you don't in the least know what it is? ... even if you come right up against it, how will you know that what you have found is the thing you didn't know?

"Socrates. ... Do you realize that ... a man cannot try to discover either what he knows or what he does not know? He would not seek what he knows, for since he knows it there is no need of the inquiry, nor what he does not know, for in that case he does not even know what he is to look for [19, pp. 31-32].

Plato's interesting argument is mainly philosophical and was discussed in the context of "virtue" vs. "knowledge". Yet searching for knowledge should not be that different from searching for information, after all. If Socrates is right, "[o]ne can never find out anything new" $[19$, p. 6], nor can search for or know about anything. So, we shall not explore it further. (For more information on Meno's Paradox, see [6].)

\section{Information and communication technologies}

Information and communication technologies (ICT) have always played a paramount role in information processing and management. Such technologies constitute the infrastructure that "makes it possible to store, search, retrieve, copy, filter, manipulate, view, transmit, and receive information" [25, p. 8]. Digital technology sharply reduces both copying and distribution costs of information by dramatically reducing the cost of making perfect reproductions and by allowing those reproductions to be distributed quickly, easily, and cheaply. No other technology has succeeded reducing both reproduction and distribution costs so far [25, pp. 84-85].

Although technology enables us to produce and distribute information cheaply, it increases the volume of available information and creates what is called "information overload". Users get inundated with information that they do not need, are unable to digest or simply have no time to "process". Reuters, the British News Agency, for example, is producing 27,000 pages of documents per second. Existence of too much information creates what is called "analysis paralysis" [34]. As the late Nobel laureate Herbert Simon put it, "a wealth of information creates a poverty of attention" [25, p. 6]. It is not enough to provide just the content: it is much more important and difficult to "attract the eyeballs" of the potential users [21, p. 42]. We need technology to help simplify processing of information by the users. Otherwise, "[t]echnology for producing and distributing information is useless without some way to locate, filter, organize and summarize it" [33, pp. 161-162]. 
The cost of storing information has sharply decreased to the extent that the cost of disk storage will soon be inconsequential (i.e., "zero") [7]. Yet the storage capacities and capabilities of various magnetooptic storage and transmission media are ever-increasing. Networks allow us to transmit large volumes of data in seconds. For example, Nortel Networks Corporation developed a new system a couple of years ago that "could transmit 1.6 trillion bits a second over a single optical fiber". To put it in context, this transmission capacity is "enough ... to transmit the contents of the Library of Congress across the country in 14 seconds" [24].

Information and communication technologies developed in recent years allow us to store all the recorded information produced by humankind throughout the centuries on a computer chip and carry it in our pockets [33]. Moreover, such a chip containing the cumulative depository of knowledge can be implanted in our heads and used as an extension of human brain. The "globalization of human knowledge" as prophesied by H.G. Wells some 60 years ago is about to become a reality, as documents and databases can be reproduced easily in a distributed environment and made accessible through the Internet [5, pp. 10-11].

\section{Information description and organization}

Storing and transmitting large amounts of information, replicating it in different places over the globe, or even making it an extension of human brain for collective intelligence still requires speedy access to and retrieval of useful information. For this, information needs to be organized. "Information to be organized needs to be described" [26, p. 53]. The description of information is then the sine qua non, "the modus operandi" of both information organization and retrieval [26, p. 206].

Describing electronic documents (web sites, logs of discussion lists, etc.) is not an easy task. The transient nature of Web documents sometimes makes it impossible to discover and describe information sources available through the Internet. Some Web documents are dynamically created "on-the-fly" while others simply disappear automatically once they fulfil their functions. The average life of a Web document is about 44 days [12, pp. 82-83]. Some disappear before they even get discovered and described by search engines. Once disappeared, both the content and its "metadata" get lost forever, as metadata is, unlike in printed documents, embedded in electronic documents. Losing the electronic document usually means losing its description as well. Any given search engine indexing only a fraction of all the Web documents does not help, either [10].

Describing documents is not a mechanical process. Search engines usually describe (index) documents on the basis of existence of certain keywords in documents using statistical techniques and term weighting algorithms. They weight and rank documents differently. Similarly, human indexers tend to assign different index terms to same documents [29]. It is sometimes impossible for various reasons to have agreed-upon definitions of certain terms such as "universal service" or "ethnic cleansing". For instance, the term "terrorism" cannot be defined to the satisfaction of all the Nations, which "has been a major obstacle to meaningful international countermeasures" [32]. ${ }^{1}$ How can then one describe documents satisfactorily on terrorism or the oil-rich Caspian "Sea" (or is it Caspian "Lake"?) The human brain organizes information by means of "associative indexing" [2, pp. 101-108]. Even though the two pieces of information are not described with the same subject keywords, the human brain can still make connections between them.

\footnotetext{
${ }^{1}$ For the history of the dispute and the European Union's definition of terrorism, see Dumitriu [4].
} 
The classification of documents is also a difficult task. George Lakoff discovered that Australian aborigines classify women, fire and dangerous things together for some reason [15]. Should "alternative medicine" be classified under health sciences, religion, philosophy, or all of the above? Is tomato a vegetable or a fruit? [23, p. 24]. ${ }^{2}$

\section{Collection management of electronic information}

In traditional libraries, owning an information source guarantees access to the contents thereof at least by one user. If the library does not own it, then users have to look elsewhere. Networked information sources are different: several users can get access to the same source simultaneously regardless of where it is located. Providing networked access is as valuable as owning the source on site. Thus, collection development and management has become a more crucial activity in information centers. Libraries are no longer limited with their own resources to provide information services to their users. Developments of Web-based information sources and services have partly coincided with exorbitant increases of prices of printed information sources, especially scientific journals, which further encouraged information managers to try new approaches other than owning resources such as licensing access and pay-per-view.

Rifkin [22] stresses that in the new economy wealth and success are measured not in terms of ownership of physical capital (plants, materials, etc.) but in terms of control of ideas in the form of intellectual and intangible capital. He briefly touches upon the "ownership vs. access" debate taking place in the library world (pp. 87-88). The Internet has been the catalyst to apply the "ownership vs. access" approach to better manage electronic information "collections". Owning information sources "just in case" users might need them is no longer the dominant method of collection development in libraries. Instead, they concentrate on providing "just in time" access to electronic sources should the users need them. This approach enables libraries to get access to more resources while, at the same time, expenditures for processing, maintenance and storage of information sources get reduced.

Vendors, on the other hand, move from subscription-based economic models to access-based models to sell information or license its use. Pay-per-view, transaction-based pricing, per-access charges, individual and institutional licenses or combinations thereof are among them. The proliferation of economic models put additional burden on collection managers. It is no longer sufficient to buy or subscribe to information sources, process, maintain and store them. Collections of libraries are not limited with what they own, maintain and archive. Information managers need to develop separate policies of processing, maintenance, storage and usage for sources that are archived or served by themselves, or accessed through mirror sites of other agencies [3]. Naturally, the responsibilities of information managers differ considerably in each case. In addition to institutional commitment, powerful computers, large data warehouses and bandwidth may be needed to process, store and transmit information for archived and served information resources, for instance.

Networked information services are gradually becoming the most heavily used services in most libraries. What should they do to cope with this increasing demand? What types of changes, if any, should be expected in their organizational and administrative structures?

"Just in time" access to electronic information sources increases user satisfaction, provides "instant gratification" and alters the use patterns of information centers. Users can conveniently consult the bibliographic databases from their own desktops located at their labs, dorms, or homes and download the

\footnotetext{
${ }^{2}$ The U.S. Government classified tomato as a vegetable for trade purposes back in 1893 by means of a Supreme Court decision (Grady [8], as quoted in Rosenfeld and Morville [23, p. 24]), although dictionaries classify tomato as a fruit.
} 
full-texts of articles from electronic journals which their library has a license for. They can place online document delivery requests for unfulfilled demand without even paying a visit to the library. The impact of electronic access to information sources appears to have been felt more heavily in the reference services and the inhouse use of libraries. The number of reference transactions was declined almost one-third in member libraries of Association of Research Libraries (ARL) while the inhouse use was almost halved since 1991. Interlibrary borrowing, on the other hand, has doubled during the last decade [14]. Consequently, the U.S. research libraries spend more for electronic resources. The total electronic serials expenditures of ARL libraries has increased more than ten-fold between 1995 and 2002 [13, slide numbers 7 and 8 ].

Information managers are faced with the challenge of providing better services with shrinking budgets. They are getting together to provide consortial access to electronic sources to get more favourable deals from information vendors. Resource sharing is facilitated by the network environment. Traditional resource sharing arrangements encouraged competition rather than cooperation in view of the benefits that large libraries accrued by owning research materials. This is no longer the case as small libraries can get access to information sources over the network with the same speed as the large ones can, regardless of where the sources are held. Furthermore, new pricing models have made the economics of cooperation more visible. Information managers are in a much better position in the new environment in terms of satisfying users' information needs, although they might not have all the wherewithal to tackle such issues as access management, long-term preservation and archiving of electronic information in consortial collection development schemes [30, pp. 292-293].

\section{Personalization of electronic information goods and services}

Mass production has been the pillar of the Industrial Era. It helps to produce the same goods in large quantities in assembly lines, thereby reducing the cost of each item produced. The famous quote, "Any customer can have a car painted any color that he wants, as long as it's black" emphasizes the fact that "Henry Ford's assembly line lowered the cost and democratised the availability of automobile, ... by narrowing choice" [21, p. 16]. The futurist Alvin Toffler, on the other hand, has first mentioned the importance of "unstandardized" goods and services for the "society of the future" in 1970s [27, pp. 234235]. Developments in computer-aided manufacturing, computer and network technologies have proved Toffler right. It is now possible to produce goods exactly as you want them (which is called customization) at the best price and highest quality. Moreover, goods can be ordered from anywhere in the world as distance is no longer a constraint. Reich labels this era as "The Age of the Terrific Deal" [21, pp. 13-26].

Customized production of a wide variety of goods and services in an economy is seen as an indication of a rich and complex society. The use of advanced information technologies makes it cheaper to produce personalized goods and services. Toffler points out that "... as technology becomes more sophisticated, the costs of introducing variations declines" ([27, p. 236]; italics in original). A wide variety of customized goods and services are available in several industries including information industry. Ondemand publishing of textbooks and newspapers, online book stores (e.g., Amazon.com), personalized news portals, banking, health, education, and travel services are among them.

Organizational structures of companies involved in mass production and mass distribution are mechanistical: the main objective is to produce more of the same products in large quantities and cheaper than their competitors. Administrative structure is hierarchical. Continuous development is rewarded. The training is traditional. Mass customization, on the other hand, requires dynamic organizational structures where the main objective is to produce what the customer exactly wants. The idea is not to sell 
more of the same products to different customers once and make more profits but to attract more customers and keep them satisfied (as it is six times more expensive to find new customers than keeping the returning ones). Administrative structure is flattened. Customer-oriented continuous training is the norm.

Electronic information services are increasingly becoming personalized within the last decade. Software packages such as MyLibrary enable users to customize and personalize their electronic information environments. They define searches, identify sources that they use most frequently and get regular search results, current awareness and table of contents (TOCs) services. They get personalized document delivery and user education services. Companies make live reference services available on every desktop computer using software packages (e.g., http://www.liveperson.com).

Electronic information services are gradually becoming integrated with automated library systems [31]. To provide seamless access to electronic information sources and services, the rights and privileges (i.e., student, faculty, remote user) of each user are defined. Automated library systems recommend certain resources on the basis of personal rights and privileges. Such "recommender systems" have been in use for some time by search engines and online book stores. Data gathered through the analysis of users' past interactions and transactions with the system (sites visited, books bought, etc.) are used to develop mass customized and personalized information systems. Products and services that might conceivably be of interest to individual users are recommended. Libraries also collect such valuable data about their users as well as use of their collections and services. Yet they are reluctant to introduce recommender systems based on such data, presumably because they are trying to tackle issues of privacy, and electronic payments of royalties, to name just a few.

Commercial companies producing personalized goods and services are going through a restructuring process to adapt to change. They become less centralized with fewer hierarchical levels and respond to user needs more quickly. So are libraries providing electronic information services. They, too, gradually switch from centralized model of information management to the distributed one. Centralized model produces information goods and services on the basis of "one size fits all" approach. Models based on personalization try to build an ongoing relationship with the users in order to recognize them and provide personal help and advice when needed.

\section{Disintermediation}

Personalization of electronic information services does not mean establishing a more "personal" relationship with the users. Information about each user (his/her characteristics, habits, use patterns, etc.) is gathered by electronic means. Users provide information about themselves to accept cookies or to get privileges of access to services. Sometimes aggregates of users are identified from transaction logs of system use. Information professionals are no longer able to "intermediate" between users and resources as a result of disappearance of face-to-face communication [31].

"Disintermediation" is one of the consequences of the applications of information technology. Some are against disintermediation solely because they lose personal touch while others see it as an opportunity to cut costs and "reintermediate" with remote users. A face-to-face transaction carried out within the building costs banks as much as six times more of what an online transaction does. Furthermore, customers usually have to wait in the line and pay for some of those face-to-face services (e.g., money orders) while they are instantly available and free of charge if carried out through the Internet. Who will miss, then, the personal touch of, and an opportunity to exchange pleasantries with, an already overloaded teller? 
Similar arguments can be put forth for personalized electronic information services as well. Faceto-face transactions cost information centers more compared to their electronic equivalents that are available through the Web. For instance, a university library comparing the costs between Web-based resources and those on its internal CD-ROM network found that average cost per search made on Webbased databases was as low as 15 cents for some databases while the average cost per search on all CD-ROMs was 15 dollars [16, p. 334]. Similar comparative figures are available for the average cost of downloading an article from electronic journals as opposed to providing it through document delivery services.

\section{Preservation and archiving of electronic information}

Continued access to electronic information is only possible through preservation and archiving. It differs significantly from that of printed sources. Preserving physical media on which information is recorded (such as books and journals) guarantees preserving the intellectual content in them. One can get access to information unless the physical medium is not damaged [9]. The first electronic mail message did not survive; no "documentary" record exists for it today.

Preservation and archiving of information stored on electronic media is quite problematic. First, the life of electronic media is relatively short compared to the more traditional media such as paper and microfiche (magnetic media: 10-30 years, optical disks: 100 years, paper: 100 years, microfilm: 300 years). Second, information-bearing objects are nowadays usually "bundled" with the technology by which their content can be deciphered: one needs computer, communication and network technologies that run multimedia software to read, hear, and view electronic documents. Both content and the technology should be preserved to get access to information.

Preservation and archiving of electronic information is based on "copying". Information recorded on old media needs to be transferred to the new media from time to time so that it will not get inaccessible due to the obsolescence of technology. New technologies do not necessarily supplant the old ones. Information published on different media (paper, microfiche, CD-ROM, etc.) will co-exist for quite some time. The copying process for preservation and archiving purposes is called "technology refreshment" or "technology migration" [20]. Information recorded on more traditional media can also be copied onto electronic media ("digitisation"). Migrating information from one medium to another may create formatting problems. New versions of a software package (used with the newer technology) may sometimes not recognize the information (e.g., footnotes) that was prepared using earlier versions of the same package. Therefore, the storage, back up, refreshment and access mechanisms needed to preserve and archive electronic information should be seen as long term investments. Organizations managing electronic information need sound IT support to integrate contents with computer and communication technologies.

While the responsibility of preserving and archiving printed information rests on libraries and archives, it is not yet clear who is responsible for the preservation and archival of electronic information. Publishers should not be relied upon for the archival copies of electronic documents, as their decisions to preserve and archive are mainly shaped by commercial motives.

Libraries on the other hand might not be solely responsible for the preservation and archival of electronic information sources for various reasons. It gets cheaper to store large volumes of electronic information in limited space. The key question is, of course, to decide what to preserve and what to discard. As this has been a most difficult decision to make in libraries, archives and museums, some 
even contemplate of preserving everything just because it is cheaper doing so. Some institutions (publishers, commercial companies, non-profit organizations such as author guilds) may wish to assume the preservation and archival of electronic information in view of economic feasibility.

Libraries and archives preserving printed sources do not usually get due credit for this task. They do not necessarily reap the benefits of owning those resources as the use is limited to one person only at any given time and location. The situation is quite different for institutions archiving electronic sources: they can provide access to those resources through the Internet regardless of time and location. This makes it attractive for publishers to get involved in archival business. Whereas storage and archival of printed sources consumes additional expenses, immediate access to archival copies of electronic information through publishers' Web sites generates new source of income for publishers.

Some publishers and non-profit organizations assume the role of long term archiving of electronic information sources published by themselves as well as other publishers. JSTOR, for instance, aims to be a reliable and long term archive of scientific journals and makes the electronic copies of those journals available through the Web. Institutions such as national libraries and universities try to become repositories of electronic copies of dissertations and technical reports. Although it remains to be seen what role libraries are to play in the preservation and archiving of electronic information, the responsibility will be assumed by more than one institution involving "individual creators, rights holders, distributors, small institutions, and other players" [11].

Preservation and archiving based on "copying" also engenders heated discussions on issues of access and copyright for electronic information. The authenticity and integrity of copied information becomes more difficult to ascertain. More research is needed to uniquely identify digital objects for description as well as for electronic commerce and royalty payments by means of electronic copyright management systems (ECMSs). Such unresolved issues make digital preservation a "time bomb" for electronic information management [11].

\section{Conclusion}

The Chinese proverb, "May you live in interesting times", appears to have already been materialized: we do live in interesting times. The famous poet Paul Valery might have thought of the same thing when he said: "The future ain't what it used to be". This is certainly the case in the provision of electronic information services. The proliferation of electronic information products and services, increasing availability of information processing, storage and communication technologies make the jobs of information managers all the more interesting. Evolving economic paradigms based on the use, rather than ownership, of electronic information sources are a challenge for electronic information managers. Libraries and information centers are no longer "the only game in town": they have to compete with other nonprofit and for-profit providers of electronic information services. Information managers have to run their non-profit library and information centers as dynamic institutions and respond quickly to the user needs. They have to adapt to changes in the immediate information, organizational and externals environments and cope with business, technology, and market pressures. They have to cooperate with other entities within their organizations to develop more innovative information services involving the use of both internal and external sources. They have to provide the best quality personalized information services as and when their users want and deliver those services to wherever their users reside. Only then can they survive, flourish, and be "better than the best". 


\section{References}

[1] M.K. Bergman, The deep Web: surfacing hidden value (2000 July). (White Paper) (Online). Available: http://www. brightplanet.com/technology/deepweb.asp (29 June 2004). Also appeared in: The Journal of Electronic Publishing 7(1) (2001) (Online). Available: http://www.press.umich.edu/jep/07-01/bergman.html (25 April 2005).

[2] V. Bush, As we may think, Atlantic Monthly 176(1) (1945), 101-108 (Online). Available: http://www.theatlantic.com/ unbound/flashbks/computer/bushf.htm (25 April 2005).

[3] Digital Library SunSITE Collection and Preservation Policy. (n.d.) (Online). Available: http://sunsite.berkeley.edu/Admin/ collection.html (25 April 2005).

[4] E. Dumitriu, The E.U.'s definition of terrorism: The Council Framework Decision on combating terrorism, Part 1 of 2, German Law Journal 5 (2004) (Online). Available: http://www.germanlawjournal.com/article.php?id=434 (25 April 2005).

[5] G.B. Dyson, Darwin Among the Machines, Penguin Books, London, 1997.

[6] D. Evans, Meno's puzzle, in: The Concept of Knowledge: The Ankara Seminar, İ. Kuçuradi and R.S. Cohen, eds, Kluwer, Dordrecht, 1995, pp. 97-102.

[7] S. Gilheany, The decline of magnetic disk storage cost over the next 25 years or when will the cost of magnetic disk storage be inconsequential for your document management application? (2002, March 29). (White paper) (Online). Available: http://www.berghell.com/whitepapers/Storage\%20Costs.pdf (25 April 2005).

[8] D. Grady, Best bite of summer, Self 19(7) (1997), 124-125.

[9] P.S. Graham, Intellectual preservation: electronic preservation of the third kind, The LIBER Quarterly 4 (1994), 163-174.

[10] L. Guernsey, Seek-But on the Web, you might not find. New York Times (1999, July 8), B8 (Online). Available: http:// www.nytimes.com (25 April 2005).

[11] M. Hedstrom, Digital preservation: a time bomb for digital libraries (1998) (Online). Available: http://www.uky.edu/ $\sim$ kiernan/DL/hedstrom.html (25 April 2005).

[12] B. Kahle, Preserving the Internet. Scientific American 276(3) (1997), 82-83 (Online). Available: http://www.hackvan. com/pub/stig/articles/trusted-systems/0397kahle.html (25 April 2005)

[13] M. Kyrillidou, E-Metrics: lessons learned from the ARL E-Metrics Project: Challenges and opportunities. Presentation delivered at the 226th American Chemical Society National Meeting, New York, NY, September 8, 2003 (Online). Available: http://www.libqual.org/documents/admin/acs_kyrillidou.ppt (25 April 2005).

[14] M. Kyrillidou and M. Young, Research library trends (2004) (Online). Available: http://www.arl.org/stats/arlstat/03pub/ 03intro.html (25 April 2005).

[15] G. Lakoff, Women, Fire and Dangerous Things: what Categories Reveal about the Mind, University of Chicago Press, Chicago, 1990.

[16] J.A. Lindley, Strategic issues in electronic librarianship, Bilgi Dünyası 1(2) (2000), 330-341.

[17] P. Lyman and H. Varian, How much information? (2003) (Online). Available: http://www.sims.berkeley.edu/research/ projects/how-much-info-2003/ (25 April 2005).

[18] E.T. O'Neill, B.F. Lavoie and R. Bennett, Trends in the evolution of the public web: 1998-2002, D-Lib Magazine 9(4) (2003) (Online). Available: http://www.dlib.org/dlib/april03/lavoie/04lavoie.html (25 April 2005).

[19] Plato's Meno, Ed. by Malcolm Brown, tr. by W.K.C. Guthrie, The Bobbs-Merrill Company, Indianapolis, NY.

[20] Preserving digital information (1996) (Online). Report of the Task Force on Archiving Digital Information commissioned by The Commission on Preservation and Access and The Research Libraries Group. May 1, 1996. Available: ftp://ftp.rlg. org/pub/archtf/final-report.pdf (25 April 2005).

[21] R.R. Reich, The Future of Success: Working and Living in the New Economy, Vintage Books, New York, 2002.

[22] J. Rifkin, The Age of Access: How the Shift from Ownership to Access is Transforming Modern Life, Penguin Books, London, 2000.

[23] L. Rosenfeld and P. Morville, Information architecture for the World Wide Web, O'Reilly, Sebastopol, CA, 1998.

[24] S. Schiesel, Nortel plans new product to bolster optical networks. The New York Times (1999, May 4) (Online). Available: http://www.nytimes.com/library/tech/99/05/biztech/articles/04nortel.html (25 April 2005).

[25] C. Shapiro and H.R. Varian, Information Rules: a Strategic Guide to the Network Economy, Harvard Business School Press, Boston, MA, 1999.

[26] E. Svenonius, The Intellectual Foundations of Information Organization, MIT Press, Cambridge, MA, 2000.

[27] A. Toffler, Future Shock, Random House, New York, 1970.

[28] A. Toffler, Powershift: Knowledge, Wealth, and Violence at the Edge of the 21st Century, Bantam Books, New York, 1990.

[29] Y. Tonta, A study of indexing consistency between Library of Congress and British Library catalogers, Library Resources \& Technical Services 35(2) (1991), 177-185.

[30] Y. Tonta, Collection development of electronic information resources in Turkish university libraries, Library Collections, Acquisitions \& Technical Services 25 (2001), 291-298.

[31] Y. Tonta, The personalization of information services, Information Management Report (August 2003), 1-6. 
[32] UNODC, United Nations Office on Drugs and Crime. Definitions of terrorism (2004) (Online). Available: http://www. unodc.org/unodc/terrorism_definitions.html (25 April 2005).

[33] H. Varian, The information economy. Scientific American 273 (1995 September), 161-162.

[34] P. Waddington, Dying for information? A report on the effects of information overload in the UK and worldwide (1997) (Online). Available: http://www.cni.org/regconfs/1997/ukoln-content/repor 13.html (25 April 2005). 
Copyright of Information Services \& Use is the property of IOS Press. The copyright in an individual article may be maintained by the author in certain cases. Content may not be copied or emailed to multiple sites or posted to a listserv without the copyright holder's express written permission. However, users may print, download, or email articles for individual use. 